\title{
O Golpe, o Ato, os Juristas e o STF Uma História da Recepção da Ditadura no Campo Jurídico
}

\author{
Mateus Gamba Torres \\ Bacharel em Direito pela Universidade Federal de Santa \\ Catarina (UFSC). Bacharel, licenciado e mestre em \\ História pela Udesc. Doutor em História pela Universi- \\ dade Federal do Rio Grande do Sul (UFRGS). Profes- \\ sor-adjunto I do Departamento de História da UNB. \\ mateustorres@ig.com.br
}

\section{Resumo}

0 golpe de Estado de 1964 foi institucionalizado por meio de uma invenção legislativa denominada Ato Institucional. 0 primeiro foi decretado dias após o golpe, alterando a Constituição, extinguindo garantias constitucionais e autorizando a perseguição de opositores. 0 presente artigo trabalha o modo como parte significativa do corpo jurídico brasileiro, a exemplo dos ministros do Supremo Tribunal Federal e juristas de renome 0 aceitaram e se adaptaram como campo as inovações legislativas ditatoriais, ao mesmo tempo que mantinham um discurso de imparcialidade perante questões políticas e de fieis aplicadores da lei.

Palavras-chave: Ato Institucional. Lei. Golpe. Ditadura.

\section{THE COUP, THE ACT, THE LAWYERS AND THE SUPREME COURT:} A HISTORY OF DICTATORSHIP RECEPTION IN THE LEGAL FIELD

\begin{abstract}
The 1964 coup was institutionalized through legislative invention called Institutional Act. The first was decreed days after the coup changing the Constitution, extinguishing constitutional guarantees and authorizing the persecution of opponents. This article deals with how significant part of the Brazilian legal body like the Justices of the Supreme Court and renowned jurists have accepted and adapted as field dictatorial legislative innovations, while that held a speech of impartiality towards political issues and of law enforcers faithful.
\end{abstract}

Keywords: Institutional Act. Law. Bang. Dictatorship.

\section{Sumário}

1 Fontes. 2 Referências. 
Dias após o golpe civil-militar de 1964, acontecimentos referentes às esferas de poder faziam notícias explodirem nos jornais em letras garrafais. Eram muitos os acontecimentos, uma revolução estava acontecendo, segundo os militares, com o objetivo de restabelecer a ordem. Para isso acontecer, o presidente da República, João Goulart, foi deposto, e o Congresso Nacional declarou vaga a Presidência da República. Assumiu o presidente da Câmara dos Deputados, Ranieri Mazzilli. Havia, porém, um procedimento constitucional a ser cumprido, ao menos teoricamente. Esse procedimento, no entanto, não previa golpes de Estado para depor presidentes e não dava respostas legais para resolver o impasse: quem iria posteriormente assumir a Presidência da República e de que forma?

A Constituição de 1946 previa que, no caso de ausência definitiva do presidente e do vice-presidente da República, assumiria o presidente da Câmara dos Deputados e seriam convocadas eleições indiretas para presidente em 30 dias, nas quais os eleitores seriam os membros do Congresso Nacional. ${ }^{1}$ Nessa ocasião, vários políticos que apoiaram o golpe de estado pretenderam se candidatar: general Kruel, ${ }^{2}$ Eurico Gaspar Dutra ${ }^{3}$ (ex-presidente). O escolhido, porém, foi o marechal Humberto Castelo Branco, militar que foi um dos executores do golpe. No dia 9 de abril de 1964, após a aprovação pelo Congresso de uma lei que regulamentava a eleição indireta para presidente da República, o Comando Militar, com o intuito de institucionalizar a revolução, decreta o primeiro de muitos outros atos institucionais. ${ }^{4}$

${ }^{1}$ Brasil. Constituição dos Estados Unidos do Brasil de 1946.

${ }^{2}$ Articula-se o nome de Kruel para Presidente. Folha de São Paulo, São Paulo 8 abr.1964. p. 1.

${ }^{3}$ Dutra também é candidato. Folha de São Paulo, São Paulo, 9 abr. 1964. p. 1.

${ }^{4}$ Alves, Maria Helena Moreira. Estado e oposição no Brasil: 1964-1984. Bauru, SP: Edusc, 2005. p. 67. 
O Ato Institucional número 1 estabeleceu a forma de eleição para o próximo presidente da República, modificou o sistema de emendas à Constituição e de aprovação de projetos de lei de iniciativa do presidente da República, suspendeu as garantias constitucionais ou legais da vitaliciedade e da estabilidade, estabeleceu investigação sumária de servidores públicos que tenham atentado contra a segurança do país, o regime democrático e a probidade da administração pública, podendo estes ser demitidos, dispensados, postos em disponibilidade, aposentados, transferidos para a reserva ou reformados, mediante atos do Comando Supremo da Revolução até a posse do presidente da República e, depois da sua posse, por decreto presidencial ou, em se tratando de servidores estaduais, por decreto do governo do Estado. Estabeleceu também a cassação dos direitos políticos de qualquer cidadão por 10 anos e de mandatos legislativos de todos os níveis.

Para que todas estas medidas fossem consideradas legítimas era necessário que houvesse uma justificação jurídica. Então após o golpe de Estado isso não tardou a acontecer. A justificativa está presente no preâmbulo do ato, no qual está explicitado que a revolução ocorrida está legitimada pela vontade do povo:

A revolução vitoriosa se investe no exercício do Poder Constituinte. Este se manifesta pela eleição popular ou pela revolução. Esta é a forma mais expressiva e mais radical do Poder Constituinte. Assim, a revolução vitoriosa, como Poder Constituinte, se legitima por si mesma. Ela destitui o governo anterior e tem a capacidade de constituir o novo governo. Nela se contém a força normativa, inerente ao Poder Constituinte. Ela edita normas jurídicas sem que nisto seja limitada pela normatividade anterior à sua vitória. Os Chefes da revolução vitoriosa, 
graças à ação das Forças Armadas e ao apoio inequívoco da Nação, representam o Povo e em seu nome exercem o Poder Constituinte, de que o Povo é o único titular. ${ }^{5}$

Pretende o Ato explicar sua própria natureza por meio de uma fundamentação jurídica em que se coloca como não limitado pela ordem constitucional vigente. Tendo em vista que havia ocorrido uma Revolução vitoriosa, esta não precisaria respeitar as leis anteriores, editando normas jurídicas sem se limitar às leis anteriormente existentes, incluindo assim a Constituição. Por isso a Revolução vitoriosa investiu-se do poder constituinte, e baseada nisso, editou o Ato Institucional que mudou a Constituição, sem precisar seguir o trâmite legislativo necessário. Os comandantes militares fundamentaram que representam o povo e em seu nome exercem esse poder constituinte. Com tal construção jurídica os militares utilizam a ideia de vontade do povo para se legitimarem e, sem limitações normativas, fazer as mudanças que consideravam necessárias na legislação. Isso justificaria a legalidade da deposição do presidente, que, no entanto, foi totalmente em desacordo com a Constituição. Deixam assim, os militares, as regras constitucionais de lado, pois estariam legitimados por algo mais profundo, a vontade do povo.

Para reduzir ainda mais os plenos poderes de que se acha investida a revolução vitoriosa, resolvemos, igualmente, manter o Congresso Nacional, com as reservas relativas aos seus poderes, constantes do presente Ato Institucional.

Fica, assim, bem claro que a revolução não procura legitimar-se através do Congresso. Este é que recebe deste Ato Institucional, resultante do exercício do Poder Constituinte, inerente a todas as revoluções, a sua legitimação. ${ }^{6}$

${ }^{5}$ Brasil. Ato Institucional, $\mathrm{n}^{\circ}$ 1, de 9 abril 1964.

${ }^{6}$ Brasil. Ato Institucional, no 1 , de 9 abril 1964. Op. Cit. 
Segundo os militares, o poder constituinte emanado da Revolução não precisaria do Congresso Nacional para se legitimar. Ainda que o Congresso representasse o povo, visto que seus membros foram democraticamente eleitos, estavam os editores do ato deixando claro que a opinião ou atitude do Congresso com relação ao golpe era indiferente, pois a Revolução é que legitimava a existência do Congresso, ou seja, por sua vontade mantinha-o funcionando.

Ainda segundo o preâmbulo do ato, a Constituição de 1946 seria mantida, pois os militares não pretendiam radicalizar o processo.

Para demonstrar que não pretendemos radicalizar o processo revolucionário, decidimos manter a Constituição de 1946, limitando-nos a modificá-la, apenas, na parte relativa aos poderes do Presidente da República, a fim de que este possa cumprir a missão de restaurar no Brasil a ordem econômica e financeira e tomar as urgentes medidas destinadas a drenar o bolsão comunista, cuja purulência já se havia infiltrado não só na cúpula do governo como nas suas dependências administrativas. $^{7}$

As mudanças na Constituição eram pontuais, porém davam ao presidente da República e aos Comandantes da Revolução poderes de suspender direitos políticos de qualquer cidadão por dez anos e de cassar mandatos, ou seja, o necessário para que não ocorresse uma oposição ao golpe de Estado, para que se instalasse um clima de medo generalizado.

Como a natureza do Ato Institucional foi explicada pelos membros do campo jurídico? À época, algumas explicações foram dadas. O ex-consultor geral da República e ex - procurador-geral da República, Carlos

${ }^{7}$ Brasil. Ato Institucional $n^{\circ} 1$, de 9 abril 1964. Op. Cit. 
Medeiros Silva, ${ }^{8}$ um dos elaboradores do Ato Institucional, em entrevista concedida e publicada na Revista de Direito Administrativo dois dias após o Ato, explica a situação do movimento militar de 1964, que posteriormente foi legalizado pela elaboração do Ato Institucional. ${ }^{9}$

Este futuro ministro do Supremo, nomeado após o AI-2, utilizou os conceitos do campo jurídico para explicar o que Bourdieu chama de mundo social. ${ }^{10}$ Afirmou Carlos Medeiros:

Sem o Ato Institucional, não teria havido uma Revolução, mas um golpe de Estado, ou uma revolta, destinados a substituir pessoas dos altos postos do Governo, conservando, porém, as mesmas regras jurídicas, os mesmos métodos de governo, políticos e administrativos, que provocaram a deterioração do poder e a sua perda. ${ }^{11}$

${ }^{8}$ Carlos Medeiros Silva nasceu em Juiz de Fora (MG) no dia 19 de junho de 1907. Formou-se em Direito no Rio de Janeiro em 1929. Após o golpe do Estado Novo foi incumbido de interpretar a nova Carta Constitucional - de autoria de Francisco Campos e cujo texto original datilografara ao tempo que fora chefe de gabinete - na parte referente à acumulação de cargos. Foi consultor geral da República e após o suicídio de Getúlio Vargas e a posse do vice-presidente João Café Filho, deixou o cargo. Em 1960 integrou a Comissão da Reforma Administrativa, exonerando-se do cargo de procurador-geral da República em 3 de dezembro desse ano, em protesto contra o presidente da República Juscelino Kubitschek, que deixara de nomeá-lo para uma vaga de ministro do Supremo Tribunal Federal (STF). Após o golpe de 1964 a junta militar, autora das primeiras transformações políticas introduzidas pelo novo regime, incumbiu Carlos Medeiros da elaboração de um ato que as formalizasse. Isso deu origem à edição do Ato Institucional no ${ }^{0}$ (AI-1), de 9 de abril desse ano, que permitiu punições extralegais de adversários do movimento, determinou a eleição indireta do presidente da República e transferiu para o Executivo importantes atribuições do poder Legislativo. Em conformidade com esse ato, foi empossado no dia 15 de abril, na Presidência da República, o marechal Humberto Castelo Branco, eleito no dia 11 pelo Congresso. Nomeado pelo marechal Castelo Branco em 27 de outubro de 1965 ministro do STF, numa das vagas abertas pelo AI-2, editado naquele mesmo dia, Carlos Medeiros tomou posse no cargo em 25 de novembro. Ainda em 1965 deixou a chefia de redação da Revista Forense. Em 18 de julho de 1966 deixou o STF e no dia seguinte tomou posse no Ministério da Justiça e Negócios Interiores. Medeiros foi o principal autor do anteprojeto da nova Constituição, que vinha sendo elaborado desde abril de 1966. Disponível em: <http:// www.fgv.br/cpdoc/busca/Busca/BuscaConsultar.aspx>. Acesso em: 10 set. 2012.

${ }_{9}^{9}$ Além de Carlos Medeiros, Francisco Campos, jurista responsável pela Constituição do Estado Novo, voltou a colaborar com a montagem de um arcabouço jurídico autoritário, nos Atos Institucionais 1 e 2. Conforme: Centro de Pesquisa e Documentação de História Contemporânea do Brasil. Francisco Campos, 2014.

${ }^{10}$ Bourdieu, Pierre. O poder simbólico. Rio de Janeiro: Bertrand Brasil, 13. ed. 2010. p. 209.

${ }^{11}$ Silva, Carlos Medeiros. Observações sobre o Ato Institucional. Revista de Direito Administrativo, n. 76, p. 473-475, abr./jun. 1964. 
Tem-se aqui a opinião de um jurista reconhecido entre seus pares como um advogado especializado em Direito Público. O jurista explica que, sem mudança na estrutura legal brasileira, o movimento de 1964 seria apenas um golpe ou uma revolta. No raciocínio do ex-procurador-geral, a mudança legal após uma tomada de poder se fazia necessária, sob pena de o movimento ser considerado apenas uma troca de postos administrativos no alto escalão do governo. Mesmo assim, não é uma explicação conceitual do Ato ou de sua natureza.

Nessa entrevista, Medeiros esforça-se para explicar a situação vigente do ponto de vista jurídico, porém apenas repetiu formalmente o que já estava escrito no próprio Ato Institucional. A entrevista, de três páginas, é dividida em seis partes, nas quais o jurista explica a adequação do Ato Institucional à realidade brasileira e a justificativa, no seu ponto de vista, explícita e convincente de que esse Ato era necessário. Para Medeiros Silva, não se tratava de um instrumento de usurpação do poder por parte dos militares, mas sim de uma ferramenta que visava à aceleração do processo legislativo, diminuindo com ele o tempo dos procedimentos referentes às reformas constitucionais e de projetos de lei. Defendeu, ainda, que o Ato se tratava de uma medida normal e necessária, e que, por fim, foi um ato cauteloso ao limitar em no máximo seis meses a suspensão das garantias constitucionais.

Nas palavras de Carlos Medeiros Silva, seria impossível enfrentar a crise social, econômica e administrativa que sofria o Brasil naquele momento sem um instrumento jurídico adequado, pois, segundo o entrevistado, ainda restavam dois anos para o final do mandato presidencial. A eleição, em sua opinião, traria cizânia e discórdia entre as pessoas, o 
que dificultaria as tarefas de acabar com a inflação crescente, a agitação e a instabilidade que reinavam no Brasil, no que ele chamou de "ditadura comunista do Governo João Goulart”. ${ }^{12}$

A tarefa gigantesca, sem a implantação de normas adequadas a sua execução, faria o governo soçobrar, talvez mesmo antes do seu período normal e ao País somente restaria aceitar, frustrando em seus anseios políticos, o advento e a permanência indefinida de um regime ditatorial. ${ }^{13}$

Apesar disso, considera que o Ato Institucional legitimou a Constituição, mantendo a estrutura do Estado, as garantias fundamentais e o Direito Privado e Público, não interferindo também no processo eleitoral que iria ocorrer em $1965 .{ }^{14}$

O jurista afirma, ainda, que não se trata de um instrumento de usurpação do poder por parte dos comandantes militares, visto que sua vigência era temporária. Não deixaria o poder constituinte de ter como fonte originária o povo, após a destituição do governo João Goulart, uma vez que deixara intactos o processo de escolha do sucessor, a data da eleição do ano de 1965, a posse, o início e a duração do futuro mandato presidencial. ${ }^{15}$

Contra o que Carlos Medeiros chamou de inércia e obstrução, o Ato visava à aceleração do processo legislativo, diminuindo o tempo dos procedimentos referentes às reformas constitucionais e aos projetos de lei. A Constituição de 1946 previa que, para aprovação de uma emenda, era necessária a votação favorável de $3 / 5$ de cada uma das Casas Legislativas. O Ato definiu a prerrogativa de o presidente propor emendas à Constituição e diminuiu o quórum necessário para a sua aprovação, para a maioria absoluta de ambas as Casas.

\footnotetext{
${ }^{12}$ Silva, Carlos Medeiros. Observações sobre o Ato Institucional. Op cit. p. 473

${ }^{13}$ Ibidem.

${ }^{14}$ Ibidem.

${ }^{15}$ Ibidem.
} 
Segundo Carlos Medeiros Silva, era uma medida normal e necessária, que autorizava o presidente da República a decretar o estado de sítio, sendo necessário apenas expor seus motivos ao Congresso Nacional. Com relação a restrições trazidas aos direitos e garantias constitucionais, o jurista explicou que tais medidas eram necessárias para a consolidação da paz, pois:

Aqueles que, no seio da administração, titulares de cargos ou funções públicas, ou privadas, vinham concorrendo para a dissolução do poder e da ordem econômica devem ser afastados desde logo. Sem a previsão, no próprio ato, das medidas e sanções aplicáveis não seria possível o expurgo. As medidas previstas com esse objetivo são normais e indispensáveis para encerrar-se qualquer ciclo revolucionário. ${ }^{16}$

A justificativa para a suspensão dos direitos individuais por seis meses era para que o governo Castelo Branco pudesse realizar a sua operação limpeza com os expurgos, aposentadorias e cassações no serviço público. Tudo isso justificado como uma fase do ciclo revolucionário.

Ao final da entrevista, Carlos Medeiros Silva afirmou que o Ato foi cauteloso ao limitar no máximo em seis meses as suspensões das garantias constitucionais. Tais explicações foram dadas apenas dois dias após a publicação do Ato. O próprio Carlos Medeiros afirma, na entrevista referida, que está estabelecendo apenas uma leitura rápida do Ato Institucional.

Num segundo momento, 20 dias depois do Ato Institucional, em artigo publicado na Revista dos Tribunais e datado de 30 de abril de 1964, Medeiros já acrescentava outras variáveis as suas explicações.

O Ato Institucional de 9 de abril de 1964 é uma lei constitucional temporária, cuja vigência, iniciada na sua data, terminará em 31 de janeiro de 1966. No período limitado, que corresponde ao Mandato do Presidente

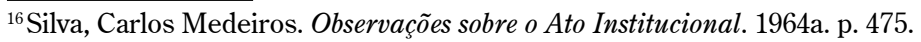


da República, eleito pela forma nele estabelecida, alguns preceitos da Constituição de 1946 deixarão de vigorar, porque outros também de natureza constitucional inscritos no próprio ato, sobre aqueles prevalecerão. ${ }^{17}$

Interessa neste momento destacar que um ex-procurador geral de Justiça aceita o poder constituinte que a Revolução advoga para si, considerando-o inclusive superior à Constituição em vigor. Isso dá um indicativo de um posicionamento de apoio ao golpe. Nos conceitos jurídicos, o poder constituinte é algo que inova. Não possui nenhum tipo de limitação nos termos das legislações anteriores, estabelece-se em casos de rupturas institucionais em que existe uma disparidade evidente e intangível entre o mundo social e o que está estabelecido na ordem estabelecida, inclusive referente à Constituição vigente no momento. ${ }^{18}$

Ainda dando explicações jurídicas ao golpe, seis meses depois de este acontecer, o jurista argumentou que as crises institucionais do período João Goulart, bem como a sua insistência em mudar as estruturas sociais no Brasil, incluindo a participação dos sindicatos e outros agentes sociais antes excluídos, justificam o golpe de Estado.

O período presidencial registrou três crises de imensas proporções, a renúncia do primeiro presidente após sete meses de exercício, a malograda experiência parlamentarista e a restauração do regime presidencialista que a cabo de pouco mais de um ano levava o país para o dramático desfecho da ditadura comunista como consequiência fatal da inflação crescente, da agitação e da instabilidade. Como enfrentar sem um instrumento jurídico adequado a crise social, política e administrativa neste curto espaço de tempo que resta do período presidencial em

\footnotetext{
${ }^{17}$ Silva, Carlos Medeiros. O Ato Institucional e a elaboração legislativa. Revista dos Tribunais, v. 53, n. 347, p. 7-17, set. 1964c.

${ }^{18}$ Lenza, Pedro. Direito constitucional esquematizado. São Paulo: Saraiva, 2008. p. 26
} 
curso, às vésperas de eleições gerais que sempre agitam as paixões e provocam a discórdia e a cizânia, mesmo entre os homens de boa vontade? ${ }^{19}$

Os argumentos da necessidade de utilização de um instrumento jurídico rápido, e de que a Constituição não conseguiria lidar com as crises institucionais que ocorreram durante o período, foram utilizados explicitamente pelo comando militar.

Para um presidente da República sofrer um impeachment, constitucionalmente seria necessário que fosse acusado e condenado pelos parlamentares por cometimento de crimes de responsabilidade. ${ }^{20}$ Isso, porém, teria de ser efetivamente comprovado, sendo que os próprios golpistas sabiam que o presidente não havia cometido nenhum delito, o que dificultaria um eventual impeachment e tornaria consequentemente impossível uma condenação neste sentido.

Isto está visível no preâmbulo do ato: "Os processos constitucionais não funcionaram para destituir o governo, que deliberadamente se dispunha a bolchevizar o país”. ${ }^{21} \mathrm{O}$ golpe se justificou, pois efetivamente, conforme a Constituição de 1946, o presidente da República não poderia ser destituído, pois que não cometera nenhum dos motivos que justificariam sua deposição.

Dentro da ordem constitucional seria impossível destituir o presidente da República. Nestes termos foi necessário um golpe de Estado revestido de Revolução e justificado como um ato que respondeu à vontade do povo para que juridicamente pudesse ser aceita a deposição do presi-

\footnotetext{
${ }^{19}$ Silva, Carlos Medeiros. Seis meses de aplicação do Ato Institucional. Revista de Direito Administrativo, n. 78, p. 449-452, out./dez. 1964b.

${ }^{20}$ Brasil. Constituição dos Estados Unidos do Brasil de 1946. Disponível em: <http://www. presidencia.gov.br/legislacao>. Acesso em: 9 jul. 2008.

${ }^{21}$ Brasil. Ato Institucional $n^{\circ}$ 1, de 9 abril 1964.
} 
dente. Com relação ao Judiciário, consideramos que dificilmente este iria se manifestar contra o golpe de Estado, tendo em vista suas características predominantes, entre elas a inércia.

Trata-se de uma característica do poder Judiciário a sua inércia, ou seja, somente pode se manifestar sobre um assunto se for provocado. ${ }^{22}$ Por isso, dificilmente o Judiciário se manifestaria contra ou a favor do golpe de Estado, a não ser que fosse chamado a se pronunciar sobre sua legalidade. Se ocorresse um impeachment, o STF seria obrigatoriamente chamado a decidir sobre o assunto em algum momento, o que não era do interesse dos comandantes militares, pois a decisão seria incerta. Com o golpe de Estado, o STF, mesmo ante a saída do presidente da República, nada poderia fazer para impedir sua ocorrência sem ser provocado. Mesmo assim, um destacado membro do campo jurídico foi convocado para dar legitimidade a um golpe de Estado, por meio da redação do ato institucional.

Outro argumento na passagem anterior demonstra que, para o jurista, a discordância e a cizânia causadas pelas eleições exigiriam um instituto jurídico adequado à situação de crise. Trata o período que restava a Goulart na Presidência de pouco tempo, mesmo que ainda faltassem quase dois anos para o final de seu mandato, e as eleições gerais que menciona ainda seriam ao menos a um ano e meio da data do golpe.

Pelo que foi possível constatar em nossa pesquisa, nenhum dos ministros do Supremo na época se declarou contrário ao golpe, o que representa uma aceitação ainda que tácita do Ato Institucional, ou ao

\footnotetext{
${ }^{22} \mathrm{O}$ princípio da inércia é aquele segundo o qual cabe à parte, ou seja, aquele que se diz titular do direito que deve ser protegido, colocar em movimento a máquina estatal (isto é, a estrutura do poder Judiciário), para que dela obtenha uma concreta solução quanto à parcela da controvérsia, ou do conflito (a essa parcela se denomina lide) trazida ao juízo. $\mathrm{O}$ poder Judiciário é completamente inerte, só se manifestando (em amplo sentido) mediante a solicitação (esta solicitação também pode ser chamada de provocação) do interessado. In: Wambier, Luiz Rodrigues. Curso Avançado de Processo civil. São Paulo: Revista dos Tribunais, 2005.
} 
menos uma posição de medo diante das circunstâncias. Com relação à posição do STF sobre o golpe, destaca-se que o presidente do STF, Ribeiro da Costa, foi à posse de Ranieri Mazzilli na noite de $1^{\circ}$ de abril, quando João Goulart ainda estava no Brasil, dando apoio à situação estabelecida. ${ }^{23}$

No dia 17 de abril de 1964, após a posse de Castelo Branco na Presidência da República, em visita deste feita ao STF, Ribeiro da Costa saudou o presidente em discurso. Emilia Viotti da Costa destacou de sua fala o argumento de que: “(...) a sobrevivência da democracia em momentos de crise se havia de fazer com o sacrifício transitório de alguns de seus princípios e garantias constitucionais.” ${ }^{4}$

Ainda segundo a autora, Ribeiro da Costa

(...) acusou o governo deposto de ser responsável pela situação em que se encontrava o país (o que também era a opinião dos militares e dos que os apoiavam), mas ressaltou que a Justiça, quaisquer que fossem as circunstâncias políticas, não tomava partido, não era a favor ou contra, não aplaudia, nem censurava, mantinha-se equidistante, acima das paixões políticas. ${ }^{25}$

O ministro admitiu ser possível uma mudança jurídica, independentemente de onde esta viesse, desde que o argumento utilizado para fazê-la fosse a manutenção da democracia. Apesar do explícito apoio aos golpistas, Ribeiro da Costa enfatizou a imparcialidade do Judiciário, elemento simbólico que, conforme Bourdieu, dá sustentação ao campo jurídico. $\mathrm{O}$ Judiciário não poderia tomar partido, teria de se manter neutro, acima de paixões políticas. Tal discurso, porém, convivia com ações que garantiram

\footnotetext{
${ }^{23}$ Disponível em <http://revistapiaui.estadao.com.br/edicao-47/questoes-juridicas/datavenia-o-supremo> Acesso em: 9 ago. 2011.

${ }^{24}$ Costa, Emília Viotti da. O Supremo Tribunal Federal e a construção da cidadania. São Paulo (SP): Ieje, 2001.

${ }^{25}$ Costa, Emília Viotti da. O Supremo Tribunal Federal e a construção da cidadania. São Paulo (SP): Ieje, 2001. p. 168.
} 
o sucesso do golpe, como a legitimação do Ato Institucional pelo presidente do Tribunal. Essa retórica de neutralidade não se observa, ainda, nas referências feitas ao presidente João Goulart, muito criticado por não manter a ordem e levar o Brasil a uma ditadura comunista.

As modificações constitucionais trazidas pelo ato institucional tiveram, pelos depoimentos expostos, uma aceitação tranquila no campo jurídico, ao menos no que diz respeito ao presidente do STF e ao renomado jurista mencionado. Dos outros ministros que faziam parte do Supremo, à época, localizamos as palavras de Evandro Lins e Silva.

Ele, que posteriormente seria cassado pelos militares, menciona a postura neutra do Supremo em relação ao golpe.

Em geral, os ministros do Supremo vivem um pouco numa torre de marfim. É claro que pode haver uma conversa, um comentário, mas não pronunciamentos. Os ministros se pronunciam nos seus votos, publicamente. E não havia nenhum caso que tivesse sido levado ao Tribunal para eles se pronunciarem sobre os atos do governo Jango.[...]

Caiu um governo, desabou um governo, foi deposto um governo. Era preciso ver as consequiências daquilo, até que se reinstitucionalizasse 0 país, e o Supremo ficou naquela expectativa, com seus juízes vitalícios, inamovíveis, aguardando. Então, veio o Ato Institucional, que era para ser o único, mas foi o primeiro, mantendo a Constituição e estabelecendo certas regras de prosseguimento do funcionamento do poder. ${ }^{26}$

Interessa notar que a postura do Supremo é de não fazer nada, manter-se no poder e procurar esperar, mesmo constatando que a ordem constitucional havia sido quebrada e havia sido deposto um governo. É muito simples perceber o discurso de neutralidade e imparcialidade, como se os ministros não devessem se envolver em assuntos políticos, e que

${ }^{26}$ Memória Jurisprudencial Ministro Evandro Lins e Silva. Disponível em: $<$ http://www. stf.jus.br/arquivo/cms/publicacaoPublicacaoInstitucionalMemoriaJurisprud/anexo/ Evandro_Lins.pdf>. Acesso em: 2 set. 2013. 
estes somente seriam decididos pelo Executivo e pelo Legislativo, ficando o Judiciário em sua torre de marfim. Nota-se, porém, a utilização deste discurso para se ficar numa posição muito confortável. Este silêncio dos ministros os mantinha no cargo.

O ministro Evandro Lins e Silva até afirma que havia um medo de que fosse cassado imediatamente após o golpe tendo em vista suas ligações anteriores com o presidente João Goulart. A visita de Castelo Branco ao Supremo, em suas palavras, foi amistosa.

Ele foi fazer uma visita protocolar ao Supremo, certo dia. Existe lá um salão que tem um grupo Luís XV com cinco cadeiras de um lado, cinco do outro, e um sofá de duas pessoas. Ficam então os dez ministros, e o presidente da República vem e senta do lado do presidente do Supremo. Quando o presidente Castelo Branco chegou, estávamos todos de pé, em torno das cadeiras, e ele se dirigiu a mim em primeiro lugar: "Ministro, como tem passado?" Eu já o conhecia, porque fui Chefe da Casa Civil e ele era o Chefe do Estado-Maior das Forças Armadas. Ele se dirigiu em seguida ao Hermes Lima e ao Victor Nunes Leal, ou seja, àqueles três que eram os mais visados pela propaganda, e depois sentou-se ao lado do presidente do Tribunal. Não falou pessoalmente com os demais. Interpretei aquilo como uma mensagem: "Não tenho nada contra os senhores”. ${ }^{27}$

O grande medo era algo individual, pessoal, ser cassado. Não se questionava o golpe, não se questionava a deposição de um governo constitucional, do qual o próprio Evandro Lins e Silva já havia feito parte, mas sim, o que se questionava era se ele e outros ministros que eram ligados a João Goulart iriam ou não serem cassados.

\footnotetext{
${ }^{27}$ Memória Jurisprudencial Ministro Evandro Lins e Silva. Disponível em: $<$ http://www. stf.jus.br/arquivo/cms/publicacaoPublicacaoInstitucionalMemoriaJurisprud/anexo/ Evandro_Lins.pdf>. Acesso em: 2 set. 2013.
} 
Nós nunca decidimos um processo contra a Revolução em si, contra o movimento militar, nós decidíamos de acordo com a Constituição: ninguém podia ficar preso além do prazo legal, ser perseguido politicamente se não havia cometido crime. O Supremo cumpriu rigorosamente a Constituição da República. ${ }^{28}$

Após o AI-5 Evandro Lins e Silva foi cassado, tendo em vista as decisões que tomou favoravelmente a políticos que eram considerados inimigos do regime. Manteve-se, porém, desde o golpe, em silêncio com relação ao que havia acontecido em $1^{\circ}$ de abril de 1964 . Mostrando que havia a necessidade de imparcialidade, afirma que nunca a revolução foi colocada no banco dos réus, por isso o seu não julgamento. A inércia judicial neste caso é utilizada como argumento para que não se faça nada em termos políticos. O Supremo cumpriu a Constituição? E a aceitação pelo Supremo do golpe de Estado? E os Atos Institucionais que mudaram a Constituição para adaptá-la ao regime? Nos Atos Institucionais fala-se em poder constituinte delegado por uma revolução, mas o próprio Lins e Silva menciona uma deposição de governo e não uma revolução.

Constata-se que todos os ministros silenciaram sobre o golpe, todos se reuniram com Castelo Branco, sem questionamentos ao golpe, aceitando a quebra da Constituição e com medo de serem cassados.

\section{FONTES}

ARTICULA-SE o nome de Kruel para Presidente. Folha de São Paulo, São Paulo 8 abr. 1964. p. 1. Disponível em: <http://acervo.folha.com.br/ fsp/1964/04/08/2/>. Acesso em: 7 set. 2012.

BRASIL. Ato Institucional no 1, de 9 abril 1964. Disponível em: <http://www. planalto.gov.br/ccivil_03/AIT/ait-01-64.htm>. Acesso em: 5 nov. 2011.

${ }^{28}$ Ibidem. 
Constituição dos Estados Unidos do Brasil de 1946. Disponível em:

<http://www.presidencia.gov.br/legislacao>. Acesso em: 9 jul. 2008.

DUTRA também é candidato. Folha de São Paulo, São Paulo, 9 abr. 1964. p. 1. Disponível em: <http://acervo.folha.com.br/fsp/1964/04/09/2/>. Acesso em: $1^{0}$ jun. 2012.

MEMÓRIA Jurisprudencial Ministro Evandro Lins e Silva. Disponível em: $<$ http://www.stf.jus.br/arquivo/cms/publicacaoPublicacaoInstitucionalMemoriaJurisprud/anexo/Evandro_Lins.pdf $>$. Acesso em: 2 set. 2013.

SILVA, Carlos Medeiros. Observações sobre o Ato Institucional. Revista de Direito Administrativo, n. 76, p. 473-475, abr./jun. 1964a. Biblioteca do Supremo Tribunal Federal.

. Seis meses de aplicação do Ato Institucional. Revista de Direito Administrativo, n. 78, p. 449-452, out./dez. 1964b. Biblioteca do Supremo Tribunal Federal.

. O Ato Institucional e a elaboração legislativa. Revista dos Tribunais, v. 53, n. 347, p. 7-17, set. 1964c. Biblioteca do Supremo Tribunal Federal.

\section{REFERÊNCIAS}

ALVES, Maria Helena Moreira. Estado e oposição no Brasil: 1964-1984. Bauru, SP: Edusc, 2005.

BOURDIEU, Pierre. O poder simbólico. Rio de Janeiro: Bertrand Brasil, 13. ed. 2010.

CENTRO DE PESQUISA E DOCUMENTAÇÃO DE HISTÓRIA CONTEMPORÂNEA DO BRASIL. Carlos Medeiros Silva. Disponível em: <http://www. fgv.br/cpdoc/busca/Busca/BuscaConsultar.aspx>. Acesso em: 10 set. 2012. CENTRO DE PESQUISA E DOCUMENTAÇÃO DE HISTÓRIA CONTEMPORÂNEA DO __ Francisco Campos. Disponível em: $<$ http://cpdoc.fgv. $\mathrm{br} /$ producao/dossies/AEraVargas1/biografias/francisco_campos $>$. Acesso em: 10 ago. 2014. 
COSTA, Emília Viotti da. O Supremo Tribunal Federal e a construção da cidadania. São Paulo, SP: Ieje, 2001.

$<\mathrm{http}: / /$ revistapiaui.estadao.com.br/edicao-47/questoes-juridicas/data-venia-o-supremo> Acesso em: 9 ago. 2011.

LENZA, Pedro. Direito constitucional esquematizado. São Paulo: Saraiva, 2008. WAMBIER, Luiz Rodrigues. Curso avançado de processo civil. São Paulo: Revista dos Tribunais, 2005.

Recebido em: $1^{\circ} / 10 / 2015$

Aprovado em: 7/1/2016 